give similar results to studies of small groups (Jarrett and Keen, 1970). It is also worthy of note that no diurnal variation in glucose tolerance was observed in the study of Hayner et al. (1965) in contrast to other reports (Roberts, 1964; Bowen and Reeves, 1967; Jarrett and Keen, 1969).

In view of the results of this investigation it is pertinent to mention that in a number of important studies of glucose tolerance in recent years the pretest fasting period was not standardized (Roberts, 1964; McDonald et al., 1965; Bowen and Reeves, 1967; Jarrett and Keen, 1969, 1970). This does not necessarily imply that the conclusions drawn from these studies are invalid. It does, however, indicate that in future studies of glucose tolerance more attention must be given to standardization of the fasting period if practical conclusions are to be derived from them.

When a glucose tolerance test is arranged, it is important that its objective should be borne in mind. If the test is carried out for a reason other than the diagnosis of diabetes, an arbitrary pretest fasting period can be chosen. This situation would obtain for example if the test is being used in a comparative study to evaluate the influence of some factor on glucose tolerance. Needless to say, the pretest fasting period should be constant, even though arbitrary.

If, on the other hand, the glucose tolerance test is being used for the diagnosis of diabetes, a standard fasting period is desirable. Otherwise it is not possible, on the basis of the results presented here, to lay down criteria of normality and abnormality. Three of the subjects over 40 years of age who were studied had diabetic glucose tolerance tests according to the criteria of the British Diabetic Association (FitzGerald and Keen, 1964). If, however, the same criteria were used with the single exception that the fasting period was eight rather than 12 hours, two further subjects would have been classified as diabetic. This suggests that one is not justified in diagnosing diabetes according to the criteria of the British Diabetic Association, or indeed according to the criteria of any scientific group, if the recom- mended test procedure in relation to fasting is not adhered to (Jarrett et al., 1972).

The results of this study suggest that the length of the pretest fast has a significant effect on the result of oral glucose tolerance tests. Strict adherence to the recommendations of the British Diabetic Association (FitzGerald and Keen, 1964) when performing oral glucose tolerance tests for diagnostic purposes, is desirable. The results reported here also suggest that other centres which allow a wide range of pretest fasting (Klimt et al., 1969) may need to review this aspect of the procedure. One of the factors which may contribute to the lack of reproducibility of oral glucose tolerance tests is the failure to ensure constant pretest fasting periods.

We acknowledge the financial support of the Medical Research Council of Ireland, and the statistical help of Dr. T. O'Donovan.

\section{References}

Bowen, A. J., and Reeves, R. L. (1967). Archives of Internal Medicine, 119, 261 .

Butterfield, W. J. H. (1966). In Diabetes Mellitus, ed. L. J. P. Duncan, p. 149. London, University Press.

Fajans, S. S. (1971). Medical Clinics of North America, 55, 793.

FitzGerald, M. G., and Keen, H. (1964). British Medical fournal, 1, 1568. Hamman, L., and Hirschman, I. I. (1917). Archives of Internal Medicine, 20, 761 .

Hayner, N. S., Kjelsberg, M. O., Epstein, F. H., and Francis, T., jun. (1965). Diabetes, 14, 413.

Hopkins, A. H. (1915). American Fournal of the Medical Sciences, 102, 254. Humphrey, C. S., Dykes, J. R. W., and Johnston, D. (1972). British Medical fournal, 4, 393.

Jacobsen, H. (1913). Biochemische Zeitschrift, 56, 471.

Jarrett, R. J., and Keen, H. (1969). British Medical fournal, 2, 341.

Jarrett, R. J., and Keen, H. (1970). British Medical fournal, 4, 334.

Jarrett, R. J., Baker, I. A., Keen, H., and Oakley, N. W. (1972). British Medical fournal, 1, 199.

Klimt, C. R., et al. (1969). Diabetes, 18, 299.

Marble, A. (1971). Foslin's Diabetes Mellitus, ed. A. Marble, P. White, R. F. Bradley, and L. P. Krall, p. 203. Philadelphia, Lea and Febiger. McDonald, G. W., Fisher, G. F., and Burnham, C. (1965). Diabetes, 14, 573. Report of Working Party appointed by College of General Practitioners (1963). British Medical fournal, 2, 655.

Roberts, H. (1964). Fournal of the American Geriatrics Society, 12, 423.

\title{
Spontaneous Periodic Hypothermia: Diencephalic Epilepsy
}

\author{
R. H. FOX, D. C. WILKINS, J. A. BELL, R. D. BRADLEY, N. L. BROWSE, W. I. CRANSTON, \\ T. H. FOLEY, E. D. GILBY, ANN HEBDEN, B. S. JENKINS, M. D. RAWLINS
}

British Medical fournal, 1973, 2, 693-695

\section{Summary}

The case of a patient with episodic hypothermia and profuse sweating believed to be due to diencephalic epilepsy is reported. Despite intensive investigations no

National Institute for Medical Research, London NW3 6RB

R. H. FOX, M.B., M.R.C.P., Member of Scientific Staff

D. C. WILKINS, M.B., CH.B., Scientist

St. Thomas's Hospital and Medical School, London S.E.1

J. A. BELL, M.B., M.R.C.P., Medical Registrar

R. D. BRADLEY, M.B., B.SC., Consultant Clinical Physiologist

N. L. BROWSE, M.D., F.R.C.S., Professor of Vascular Surgery

W. I. CRANSTON, M.D., F.R.C.P., Professor of Medicine

T. H. FOLEY, M.D., M.R.C.P., Lecturer in Medicine

E. D. GILBY, M.R.C.P., Registrar in Endocrinology

ANN HEBDEN, Chief Technician, E.E.G. Department

B. S. JENKINS, M.B., M.R.C.P., Senior Lecturer in Clinical Physiology

M. D. RAWLINS, B.SC., M.R.C.P., Lecturer in Medicine other manifestations of hypothalamic dysfunction were found. Conventional antiepileptic drugs were without efiect but the patient was successfully treated by total sympathectomy.

\section{Introduction}

Spontaneous periodic hypothermia associated with profound sweating is a rare condition involving a severe disturbance of thermoregulatory control. We report the investigation and successful management of such a case which showed a number of distinctive features.

\section{Present Study}

CASE REPORT

A 49-year-old veterinary assistant was admitted to the Hospital for Tropical Diseases in October 1969 under the care of Professor A. W. 
Woodruff. Apart from meningitis in childhood, which had left her with no apparent disability, and a hysterectomy in 1955 she had enjoyed good health until three years before admission. She had then developed attacks of sweating associated with cutaneous flushing lasting 10 to 20 minutes which was followed by a sensation of cold and often shivering. Rectal temperature fell during attacks and was recorded as low as $34^{\circ} \mathrm{C}$. Initially attacks occurred once or twice a day but gradually increased so that by 1969 they appeared every one and a half to two hours and necessitated several changes of bedclothes at night. She was otherwise well and had no neurological symptoms apart from occasional disturbances of memory and slight confusion after her sweating attacks.

Examination showed nothing abnormal. The haemoglobin was $13.6 \mathrm{~g} / 100 \mathrm{ml}$, white blood count $4,600 / \mathrm{mm}^{3}$, and erythrocyte sedimentation rate $32 \mathrm{~mm}$ in one hour. Urinary excretion of vanillyl mandelic acid $(2.3 \mathrm{mg} / 24 \mathrm{hr})$ and catecholamines $(0.1 \mathrm{mg} / \mathrm{ml})$ was normal. The Wassermann reaction was negative but direct agglutinins for Brucella abortus were present at a titre of $1 / 640$ and for $B r$. melitensis at a titre of $1 / 160$ and the brucella complement fixation test was positive at $1 / 256$. In view of this evidence of chronic active brucellosis she was treated with streptomycin $0.5 \mathrm{~g}$ twice daily, sulphadimidine $1 \mathrm{~g}$ twice daily, and tetracycline $500 \mathrm{mg}$ four times a day for 66 days with no improvement in her symptoms.

She was transferred to St. Thomas's Hospital, London, for further investigations. Again physical examination showed no abnormality. Examination of the visual fields by perimetry and with Bjerrum's screen showed no defect. Findings on skull radiography, tomography of the pituitary fossa, lumbar air encephalography, and radioisotope brain scan were normal. An E.E.G. showed bilateral, generalized episodic bursts of 2 to $3 \mathrm{~Hz}$ delta activity indicative of a deep midbrain lesion, but a continuous record throughout an attack did not show any additional abnormality. Urinary excretion of 5-hydroxyindole acetic acid was $4.4 \mathrm{mg} / 24 \mathrm{hr}$ (normal). Plasma corticosteroids rose from $13 \mu \mathrm{g} / 100 \mathrm{ml}$ to $26 \mu \mathrm{g} / 100 \mathrm{ml}$ after intravenous insulin $(0.1 \mathrm{U} / \mathrm{kg}$ body weight) and plasma growth hormone rose from $2.0 \mu \mathrm{U} / \mathrm{ml}$ to $60 \mu \mathrm{U} / \mathrm{ml}$ (normal). An intravenous injection of bacterial pyrogen $\left(0.28 \mu \mathrm{g} \mathrm{E}\right.$ pyrogen) caused a rise in temperature of $1.25^{\circ} \mathrm{C}$; at the same time plasma cortisol rose from $10 \mu \mathrm{g} / 100 \mathrm{ml}$ to $29 \mu \mathrm{g} / 100 \mathrm{ml}$ at three hours and plasma growth hormone from $2.0 \mu \mathrm{U} / \mathrm{ml}$ to $49 \mu \mathrm{U} / \mathrm{ml}$ (at two hours). The circadian rhythm of plasma corticosteroids was shown to be normal in consecutive four-hourly samples taken over 24 hours. Urinary circadian rhythms were tested as described by Payne and De Wardener (1958) and normal patterns were found for volume, osmolality, and excretion of creatine, sodium, potassium, and phosphate. Serum luteinizing hormone was $346 \mu \mathrm{g} / \mathrm{ml}$ (high).

Venous blood glucose during an attack was $70 \mathrm{mg} / 100 \mathrm{ml}$. After an attack blood was withdrawn from a brachial artery catheter at 1,6 , $11,16,26$, and 36 minutes for assays of cortisol, insulin, growth hormone, thyroid stimulating hormone, adrenocorticotrophic hormone, and neurophysin. No change in the plasma concentrations of any of these hormones was found.

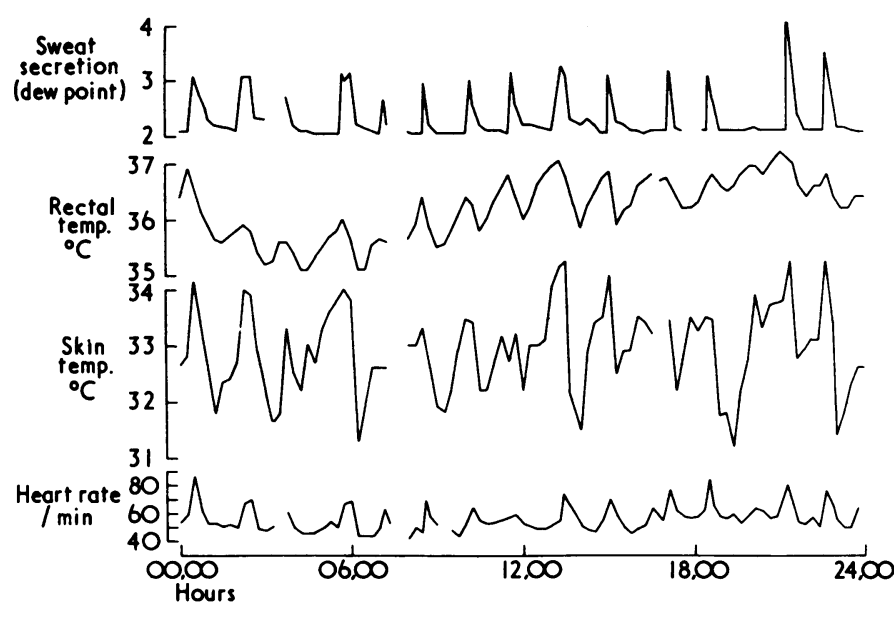

FIG. 1-Twenty-four-hour record of patient showing increase in temperature and water loss from skin and decrease in deep body temperature associated with attacks.

\section{SPECIAL INVESTIGATIONS}

Twenty-four Hour Record of Attacks.-For a 24-hour period the patient was observed with an indwelling rectal thermistor thermometer, a skin thermistor thermometer on the neck, and a ventilated capsule on the arm measuring water loss from the skin. Fig. 1 shows 15 attacks in the 24 hours occurring with a periodicity of about 90 minutes. There were concomitant decreases in rectal and increases in skin temperature coinciding with the bursts in sweating.

Detailed Investigation of Single Attack.-Fig. 2 shows the changes in the skin and rectal temperatures, sweating, blood

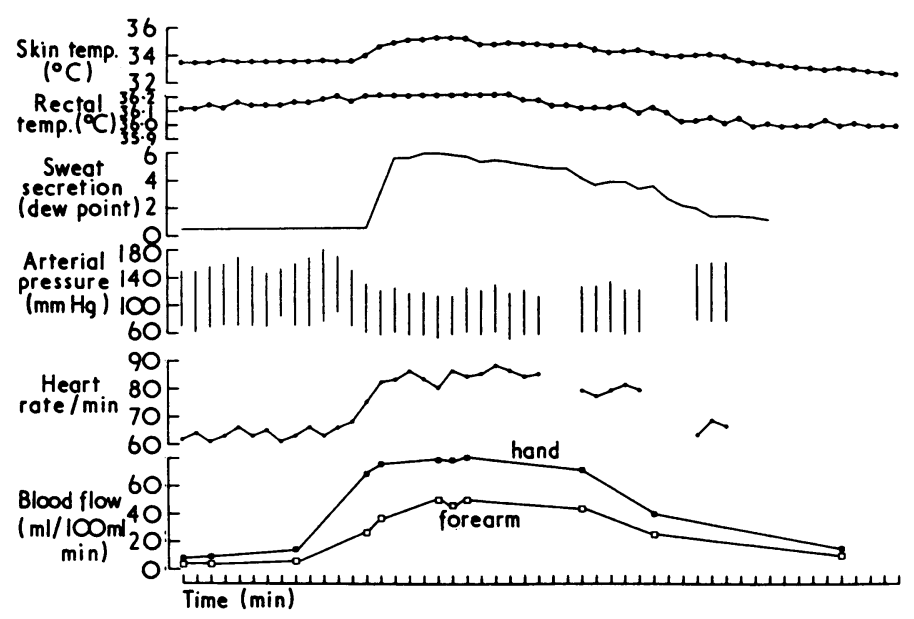

FIG. 2-Changes in deep body and skin temperatures, sweating, blood pressure, heart rate, and hand and forearm blood flows during an attack. pressure, heart rate, and hand and forearm blood flows during

pressure (brachial artery catheter), heart rate, and hand and forearm blood flows (venous occlusion plethysmography) during an attack. At the start of the attack there were simultaneous and dramatic increases in skin temperature and hand and forearm blood flows with a progressive fall in rectal temperature. At the same time blood pressure fell and heart rate increased. The cardiovascular changes were consistent with a sudden and marked peripheral vasodilatation. The attack ended with a more gradual return to normal levels of all the variables measured.

Hyoscine Iontophoresis.-A normal neurogenic basis for the secretion of sweat during an attack was shown by iontophoresis of hyoscine butylbromide (at $0.5 \mathrm{~mA}$ for $7.5 \mathrm{~min}$ ) into an area of forehead skin. Sweat secretion was suppressed over the treated skin during the next attack.

Air-conditioned Bed Test.-To investigate the possibility that attacks were triggered by deep body temperature or by skin temperature rising to critical levels the patient was studied on an air-conditioned bed as described by Fox (1967). She was dressed in a vapour-barrier suit to prevent evaporation of sweat. In the experiment illustrated in fig. 3 the aim was to keep skin temperature at around $30^{\circ} \mathrm{C}$ in the absence of attacks while introducing heat to raise deep body temperature by warming one arm in a water bath at $44^{\circ} \mathrm{C}$. The results show that despite a skin temperature of $30^{\circ} \mathrm{C}$ three attacks occurred with a similar periodicity to those shown in fig. 1. Cooling of the bed did not abort an attack once it had begun. The deep body temperature at which the three attacks occurred varied between 36.0 and $37.0^{\circ} \mathrm{C}$. These findings ruled out a critical skin or deep body temperature level as the trigger for an attack. The fact that the responses were rather smaller when the patient was being cooled may provide a mechanism for avoiding profound hypothermia. 


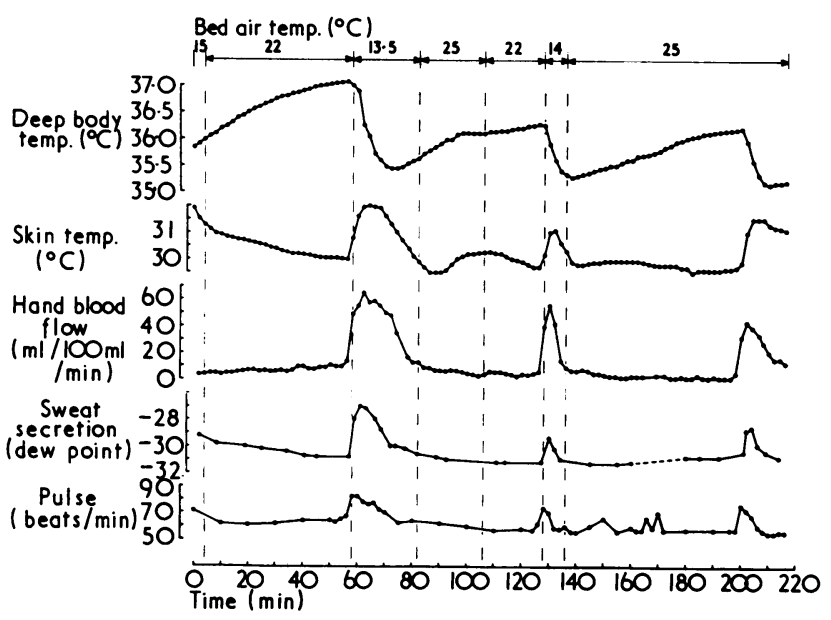
FIG. 3 - Changes in deep body and skin temperatures, sweat secretion, hand controlled climate using air-conditioned bed. Maintaining skin temperature controlled climate using air-conditioned bed. Maintaining skin temperature
at $30^{\circ} \mathrm{C}$ did not prevent attacks, and once started attack could not be aborted at $30^{\circ} \mathrm{C}$ did not pre
by further cooling.

\section{TREATMENT}

The investigations outlined excluded the common causes of generalized hyperhidrosis, and as discussed below it was felt that the attacks were epileptiform in origin. An attempt was therefore made to suppress the symptoms with antiepilepric drugs. Treatment with phenobarbitone (180 $\mathrm{mg}$ daily), phenytoin (300 mg daily), carbamazepine ( $400 \mathrm{mg}$ daily), primidone (250 $\mathrm{mg}$ daily), and haloperidol ( $4.5 \mathrm{mg}$ daily) did not affect the frequency or intensity of the episodes. No symptomatic relief was obtained from the use of systemic pempidine $(8.0 \mathrm{mg}$ daily) or from the topical application of poldine sulphate. In the absence of any other useful therapeutic manoeuvres and because the patient's symptoms continued to an incapacitating extent it was felt that only sympathectomy could offer relief. Bilateral cervical sympathectomy was performed on 13 May 1971 (N.L.B.).

After this there was complete cessation of sweating above the level of T 3 on both sides during attacks. Right and left thoracolumbar sympathectomies were carried out on 3 and 22 June 1971 respectively. Postural hypotension occurred after the operations but was controlled by the use of elastic stockings, fludrocortisone (0.3 $\mathrm{mg}$ daily), and ephedrine (180 $\mathrm{mg}$ daily). Three months after the operation the patient noticed sweating attacks involving the left foot and a small area over the right shoulder. These persisted but were not incapacitating. After a four-year absence she was able to return to work.

\section{Discussion}

Persistent low body temperatures due to partial or complete thermoregulatory failure and usually with some evidence of hypothalamic damage is a well-documented syndrome (Bauer, 1954; Bannister, 1963; Macmillan et al., 1967; Fox et al., 1970). Episodic hypothermia with profound sweating due to hypothalamic damage has previously been reported in only five patients (Penfield, 1929; Hines and Bannick, 1934; Hoffman and Pobirs, 1942; Duff et al., 1961; Cunliffe et al., 1971), and in only one (Penfield, 1929) was an anatomical lesion shown. In our patient the E.E.G. abnormalities, the co-ordinated thermoregulatory nature of the episodes, and the favourable response to sympathectomy were consistent with diencephalic epilepsy, though the underlying disorder was not clear and the condition failed to respond to antiepileptic drugs.

In reported cases the duration and frequency of attacks have varied widely from only one attack daily lasting three to four hours (Hoffman and Pobirs, 1942; Duff et al., 1961) to the present case with attacks occurring day and night but lasting only 30 minutes. In some patients there has been additional evidence of autonomic disturbance-for example, salivation and lachrymation (Penfield, 1929) and nausea and vomiting (Hoffman and Pobirs, 1942; Hines and Bannick, 1934); these were not present in our patient and despite extensive investigations no other evidence of disturbed hypothalamic function could be found. Unlike the case described by Cunliffe et al. (1971) the attacks in this patient were not triggered by warming.

Three of the five previously recorded cases responded favourably to antiepileptic drugs (barbiturates or bromide) (Penfield, 1929; Hines and Bannick, 1934; Hoffman and Pobirs, 1942), one was controlled by the topical application of poldine sulphate (Cunliffe et al., 1971), and one underwent spontaneous remission (Duff et al., 1961). In our patient drug therapy was ineffective but total sympathectomy proved successful and enabled her to return to work.

The investigations on this patient are of particular interest to thermal physiologists. Part of the rapid fall in deep body temperature seen during attacks was due to the sudden and inappropriate increase in blood flow through the skin, which evens out the core-shell temperature difference; this is best shown by the experiment (fig. 3) in which evaporation of sweat was prevented. During an attack peripheral blood flows and sweat rate were considerably higher than those found in normal subjects after sympathetic blockade (Foley, 1970), probably owing to the development of heat acclimatization through frequent use of the heat-dissipating mechanisms.

The heat-dissipating response was completely co-ordinated, consisting of sweating with widespread cutaneous vasodilatation. Despite falls in deep body temperature to hypothermic levels the heat-conserving mechanisms were completely inhibited until the attack subsided, when they became prominent.

This clear manifestation of episodes of co-ordinated heat loss suggests either that there is some spatial separation of regions of the brain responsible for heat conservation and dissipation or that different neurotransmitters are concerned with these functions. In the latter case it would be necessary to postulate specific release of one transmitter substance during attacks.

Brucella agglutinations and complement fixations were carried out by the Brucella Reference Laboratory, Portsmouth.

\section{References}

Bannister, R. G. (1963). D.M. thesis, Oxford.

Bauer, H. G. (1954). Yournal of Clinical Endocrinolosy, 14, 13.

Cunliffe, W. J., Johnson, C. E., and Burton, J. L. (1971). British Yournal of Dermatology, 85, 186 .

Duff, R. S., Farrant, P. C., Leveaux, V. M., and Wray, S. M. (1961) Quarterly Yournal of Medicine, 30, 329.

Foley, T. H. (1970). M.D. thesis, London University.

Fox, R. H. (1967). Occupational Health Program, National Center for Urban and Industrial fealth, Public Health Service, Technical Report, No. 44, p. 267. Washington.

Fox, R. H., Davies, T. W., Marsh, F. P., and Urich, H. (1970). Lancet, 2 , 185.

Hines, E. A., jun., and Bannick, E. G. (1934). Proceedings of the Staff Meetings of the Mayo Clinic, 9, 705 .

Hoffman, A. M., and Pobirs, F. W. (1942). Fournal of the American Medical Association, 120, 445.

Macmillan, A. L., et al. (1967). Lancet, 2, 165.

Payne, R. W., and De Wardener, H. E. (1958). Lancet, 1, 1098.

Penfield, W. (1929). Archives of Neurology and Psychiatry, 22, 358. 